\title{
Entre o nacional e o regional: Uma reflexão sobre a importância dos recortes espaciais na pesquisa e no ensino da História
}

André Roberto de Arruda Machado*

Resumo: Ao propor a discussão de qualquer problema, seja ao ensinar ou pesquisar, o historiador sempre faz um recorte espacial que julga ser o mais adequado para compreender o objeto em estudo. Esse é um problema crucial para qualquer historiador, mas ainda mais evidente para aqueles que estudam ou vivem em regiões consideradas como periféricas, como o Pará, já que a história tida como "nacional" frequentemente ignora ou relega ao segundo plano os eventos ocorridos nesses locais. Partindo de exemplos de pesquisa sobre a história do Grão-Pará durante a independência e o Império do Brasil, este artigo pretende refletir sobre quatro pontos principais: 1) O recorte espacial é uma questão metodológica e, como tal, reflete a visão de mundo do historiador professor/ pesquisador; 2) O potencial do estudo e ensino sobre regiões periféricas para problematizar as grandes questões nacionais; 3) A necessidade de problematizar os eventos locais dentro de contextos mais amplos; 4) Os diferentes sentidos da "história regional" em São Paulo e no Pará.

Palavras-chave: Metodologia. Recortes espaciais. Grão-Pará.

\footnotetext{
* Doutor em História Social pela Universidade de São Paulo - USP. Professor Adjunto da Universidade Federal de São Paulo - UNIFESP. E-mail: andremachados@yahoo.com.br
}

Anos 90, Porto Alegre, v. 24, n. 45, p. 293-319, jul. 2017 
Entre o nacional e o regional: uma reflexão sobre a importância...

\section{Entre centros e periferias: uma batalha historiográfica}

Quem, até o início da recente reforma, visitava ou trabalhava no Museu Paulista da USP - popularmente conhecido como Museu do Ipiranga - via todos os dias professores e uma grande quantidade de alunos dos ensinos fundamental e médio em seus corredores. Não é por acaso que esta é uma das instituições mais procuradas do gênero na cidade de São Paulo. O grande fascínio da população e dos turistas pelo Monumento à Independência, depois transformado em museu, deve-se à consagração da ideia de que ali os visitantes estão "vivenciando a história", seja por estarem no sítio onde D. Pedro bradou "Independência ou Morte!" ou porque a todo momento visualizam retratos e objetos de personagens tidos como protagonistas da história nacional. (OLIVEIRA, 2002, p. 65-80).

Sem uma leitura crítica, este impacto visual leva o professor e o aluno a crerem que estão diante de um retrato da história e não de um recorte que tem como um dos seus objetivos ressaltar a importância de São Paulo na construção da nação brasileira. ${ }^{1}$ Nesse sentido, um dos grandes apelos do monumento-museu, que o faz lotar em todas as comemorações do sete de setembro, é a concepção de que ali se fez a independência do Brasil. Sem recorrer à ampla bibliografia que deixa evidente que o Estado e a nação brasileira não nasceram no ímpeto do "grito do Ipiranga" (JANCSÓ, 2005; MACHADO, 2010), bastaria para desiludir o visitante a informação de que o "sete de setembro" teve um caminho tortuoso até ser considerado uma efeméride nacional e que em muitos momentos isto atendeu a interesses marcadamente paulistas. Hendrik Kraay, por exemplo, demonstra que já em 1822 havia o projeto entre os paulistas de criar um monumento no Ipiranga para consagrar a data, mas no planejamento das festividades do Império para 1823 essa comemoração foi solenemente ignorada (KRAAY, 2010). Cecília Helena de Salles Oliveira é ainda mais radical que Kraay: insiste que os jornais da época jamais deram ao sete de setembro o sentido de ruptura com Portugal que a historiografia consagrou. Segundo ela, o esforço para consagrar a data na constituinte de 1823 partiu da bancada paulista que era defensora do monumento já citado (OLIVEIRA, 2002). Kraay demonstra que ao longo do primeiro reinado, o sete de setembro foi incluído e excluído

Anos 90, Porto Alegre, v. 24, n. 45, p. 293-319, jul. 2017 
por diversas vezes dos projetos que visavam definir as datas nacionais. Em várias ocasiões o sete de setembro foi desbancado pelos defensores do 12 de outubro - data da coroação de D. Pedro I - como data da fundação do Império. $\mathrm{Na}$ primeira legislatura, até mesmo uma voz como a do deputado Vergueiro - um dos mais importantes parlamentares de São Paulo - considerou o sete de setembro como uma data de importância apenas regional. Como explica Kraay é apenas na Regência, por conta da repulsa a D. Pedro I que acabara de abdicar, que o 12 de outubro perde força e o sete de setembro consolida-se. Ainda assim, este processo só será completado nas décadas de 1850 e 1860 (KRAAY, 2010; OLIVEIRA, 2002).

Esse recorte do passado não se presta a construir o protagonismo de São Paulo na história nacional apenas na escolha do sítio onde está o monumento-museu. É no interior do edifício que os episódios em terras paulistas deixam de ser uma particularidade para se fixar como o motor da história nacional. A exemplo de outros autores, Cláudia Mattos deu grande destaque à decoração interna do museu, que foi idealizada, para as comemorações do centenário da independência, por seu diretor Affonso Taunay. Não se deve esquecer que Taunay se notabilizou pelo esforço em fixar os bandeirantes paulistas como os heróis que desbravaram o território americano e teriam garantido ao Brasil o seu tamanho atual. ${ }^{2}$ No enorme hall de entrada, o visitante não pode deixar de notar duas enormes estátuas de bandeirantes, uma de cada lado da entrada, que formam um conjunto com as ânforas cheias de águas de cada um dos grandes rios brasileiros apoiadas nas escadas monumentais. Acima das ânforas, quadros de bandeirantes com os nomes de estados que anteriormente pertenceram ao território considerado paulista. No meio da escada monumental, ao lado dos quadros dos bandeirantes e acima das ânforas, a estátua de D. Pedro I em um gesto heroico, prenunciando a catarse do visitante que se dá no salão nobre, em frente ao famoso e gigantesco quadro "Independência ou Morte!" de Pedro Américo, onde ganha materialidade a ideia do nascimento da nação em terras paulistas. ${ }^{3}$

O que se quer chamar a atenção é para o fato de que poucos visitantes e professores observariam as enormes figuras e quadros dos bandeirantes e seriam remetidos a uma ideia de "história 
Entre o nacional e o regional: uma reflexão sobre a importância...

regional"'. O museu é apenas a síntese de um projeto historiográfico vitorioso, que fundiu a história de São Paulo à própria história da nação. Sintomaticamente, as grandes universidades em São Paulo não têm matérias especificas obrigatórias sobre a história em território paulista. Essa é uma situação bem distinta da maior parte das universidades em outros estados. No Paraná, Rio Grande do Sul e Pernambuco, as suas mais tradicionais universidades federais dedicam à formação dos futuros historiadores pelo menos uma disciplina obrigatória de história circunscrita ao território desses estados. ${ }^{4} \mathrm{No}$ Ceará e no Maranhão, o número de disciplinas com esse teor chega a três obrigatórias, quase o mesmo número dedicados ao estudo do Brasil como um todo. ${ }^{5}$ No Pará, tem-se o caso mais extremo entre os pesquisados: quatro disciplinas obrigatórias dedicadas à história e a historiografia da Amazônia, exatamente o mesmo número das oferecidas ao estudo do Brasil. ${ }^{6}$ Como extensão desse fenômeno, é bastante significativo que nas universidades os historiadores que analisam o Império do Brasil com o foco em outros estados que não São Paulo, Rio de Janeiro e Minas Gerais, sejam tradicionalmente identificados como "regionalistas", algo que dificilmente acontece com o primeiro grupo.

Nos ensinos fundamental e médio essa dinâmica se repete. Em vários Estados do Brasil, tradicionalmente, parte do conteúdo da disciplina História é voltada aos eventos que ocorreram nesses territórios (BITTENCOURT, 2009, p. 160-164). Ao analisar algumas das orientações curriculares estaduais isso é evidente, ainda que as abordagens sejam diferentes. Na rede pernambucana, por exemplo, os "Parâmetros para a Educação Básica" de 2013, previam que o ensino de História de Pernambuco seria um dos três eixos temáticos que percorriam toda a segunda etapa do ensino fundamental e médio. ${ }^{8}$ Nas escolas públicas goianas, o "Currículo Referência" de 2012 sugeria uma presença constante da História de Goiás, muitas vezes como contraponto ou complemento às temáticas da História do Brasil. ' Como último exemplo, no Rio Grande do Sul o referencial curricular de 2009 dedicou, quase exclusivamente, toda a quinta série ao estudo da História deste estado, além do assunto voltar a aparecer esporadicamente em anos seguintes. ${ }^{10}$ 
As próprias políticas públicas nacionais deixam perceptível como isso foi incorporado. No início da década de 1990, Sandra Jatahy Pesavento já assinalava que as diretrizes da política educacional nacional "enfatizaram a necessidade de regionalizar os currículos", algo com impacto direto para a disciplina de história no Ensino Básico (PESAVENTO, 1990, p. 67). Como consequência, o último PNLD (2016) demonstra a força dessa tradição, com a disponibilização de vários livros didáticos do ensino básico dedicados a contar uma história circunscrita ao território do estado dos alunos. ${ }^{11}$

Mais do que isso, a atual discussão da Base Nacional Curricular Comum (BNCC) para a disciplina de História, demonstra a centralidade dessa questão. Curiosamente, poucos puseram em xeque o próprio significado da uniformização dos currículos e quanto isso afeta uma ação central da atividade docente: a de identificar e selecionar os assuntos relevantes para a formação dos seus alunos (SILVA, 1999; BITTENCOURT, 1998). Ao contrário disso, foi possível perceber que as críticas e as defesas do estabelecimento das BNCC estiveram concentradas no atendimento ou supressão de temáticas ou eventos específicos. $\mathrm{Na}$ defesa dos formuladores da BNCC esteve o argumento que interessa a este artigo: a de que as Bases nunca ultrapassariam $60 \%$ do currículo escolar de cada ano escolar, portanto cabendo ao professor autonomia para questões específicas. Mais de uma vez, ficou explícito que parte significativa dessa autonomia na construção do currículo estava reservada ao que se entendia como especificidade regional. Para não restar dúvidas da pertinência dessa observação, o próprio ex-ministro da Educação Renato Janine Ribeiro usou a disciplina História para exemplificar o que seriam essas especificidades regionais que deveriam ser contempladas nos currículos:

Embora nossa língua seja a mesma no país todo, nós temos formas de construí-la e de usá-la diferentes, conforme a região e o estado. É importante que quem nasça na região da Amazônia saiba e desenvolva a história da colônia que se chamou Grão-Pará, que era separada da colônia no Brasil. Eu não aprendi isso na escola. ${ }^{12}$ 
Entre o nacional e o regional: uma reflexão sobre a importância...

Apesar da força dessa tradição na maior parte do Brasil, a ponto de pautar políticas do Ministério da Educação, mais uma vez essa não é uma realidade em São Paulo. De modo geral, não há espaços nas escolas paulistas para discutir especificamente a história desse estado. Essa característica pode ser vista de forma ainda mais evidente recentemente, já que nas últimas gestões do governo estadual resolveu-se criar um currículo mínimo. Para alcançar esse objetivo, o governo de São Paulo instituiu a distribuição de um material didático único para toda a rede, adotando uma estratégia muito próxima do que conhecemos como "sistema apostilado de ensino". ${ }^{13}$ Ao observar a Proposta Curricular do Estado de São Paulo: História, podemos perceber que mesmo os capítulos dedicados especificamente ao Brasil ou à América Portuguesa no ensino médio, por exemplo, não passam de um quarto do total, algo que já demonstra o alinhamento à tendência da chamada "história integrada" muito em voga nos materiais didáticos. ${ }^{14}$ Se nessa proposta curricular há poucos momentos específicos dedicados ao Brasil ou à América Portuguesa, não é surpreendente que não exista nenhum capítulo exclusivo sobre episódios ocorridos em São Paulo.

A despeito da situação em São Paulo, temos um fenômeno historiográfico muito arraigado no Brasil, mas pouco debatido. Afinal, o que significa "História Regional”? Quando um episódio, necessariamente circunscrito a um território específico, deixa de ser parte de uma "História Regional"? Uma breve consulta aos anais dos dois últimos Encontros Nacionais de História da ANPUH, em 2013 e 2015, revela a quase inexistência de qualquer simpósio dedicado a esse tema, fosse para compartilhar experiências empíricas ou promover uma discussão metodológica crítica. Dos mais de 200 simpósios organizados, sobre as temáticas mais diversas, apenas um, em 2013, foi dedicado ao debate da "história regional", por sua vez vinculando essa discussão ao ensino de história para a educação básica. ${ }^{15}$ Não é por acaso: debates sobre "história regional" ou mesmo a chamada "história local" parecem hoje promover uma discussão mais intensa no ensino de história do que em outras áreas. Talvez isso se dê pela força das diretrizes da política educacional nacional citadas acima, ou pela crença de correntes pedagógicas, hoje questionadas, que preconizam que o ensino deve se dar do 
mais concreto, ou do mais próximo do aluno, ao mais abstrato (PESAVENTO, 1990, p. 70).

Talvez a discussão nacional mais intensa sobre esse tema continue sendo aquela promovida pela ANPUH na década de 1980 e que depois foi publicada em livro organizado por Marcos Antonio Silva com o título República em migalbas: história regional e local (SILVA, 1990). Nessa ocasião, diversos historiadores buscaram problematizar o conceito de "regional", procurando apoio em diversos outros campos do conhecimento, notadamente a geografia. Lidos em conjunto, os debates parecem expressar a arte básica de qualquer historiador: o recorte espacial de um pesquisador deve estar alinhado ao problema a ser investigado e não circunscrito a priori. No entanto, como muito bem sintetizado por Rosa Maria Godoy Silveira, no Brasil ocorreu uma "entificação" do que se entende por "História Regional". Dessa maneira, coube aos territórios dos Estados da federação o papel desse "ente" (SILVEIRA, 1990), tendo, como regra, a descrição de episódios desconectados de contextos maiores, ilhados nas fronteiras das antigas províncias.

Nessa operação, o recorte espacial não é definido pelo problema historiográfico a perseguir, mas por uma obrigação pretérita de salvaguardar episódios ocorridos no interior do território dos estados da federação que seriam condenados ao "buraco negro" da história nacional. Contudo, como tem destacado alguns pesquisadores, a história regional ou local, especialmente dedicada ao ensino na educação básica, muitas vezes tem se prestado apenas a conservar a memória e o prestígio de grupos locais ou a reproduzir uma história de culto aos grandes homens já abandonada por outras abordagens historiográficas. ${ }^{16}$ Qual o sentido, por exemplo, de um livro didático sobre a história do Pará reservar um capítulo inteiro à única visita de D. Pedro II à província, contando refeições, rezas e outros pormenores, tratando-se de uma simples escala para os Estados Unidos que durou não mais do que quatro horas (ROQUE, 2001, p. 76-79)? Por que comemorar a efeméride e não problematizar a distância dos centros de poder ou o papel das festas nos século XIX? E o que dizer do festejado plano de abolição da escravidão no Pará que não ocorreu porque a lei áurea o antecipou em um ano (ROQUE, 2001, p. 74-75)? 
Entre o nacional e o regional: uma reflexão sobre a importância...

Ainda faz sentido ter como centro da preocupação de um trabalho historiográfico ou de ensino, episódios ocorridos fora de São Paulo, Rio de Janeiro ou Minas Gerais? Este artigo buscará demonstrar que sim, mas por uma razão inversa da defendida por Renato Janine Ribeiro, o ex-ministro da Educação a implementar o BNCC: como citado acima, para ele era importante que um aluno do Pará conhecesse a existência de uma colonização portuguesa na América em paralelo com o Estado do Brasil, como uma forma de entender a sua própria identidade. Ao contrário disso, parece-nos evidente que esse é um conhecimento que interessa a qualquer aluno e, até mesmo, à formação de qualquer historiador. Busca-se uma história que selecione episódios ocorridos fora do centro de poder, não para preencher uma lacuna, mas para contemplar problemas em toda a sua complexidade.

Certamente, para um aluno e mesmo para um professor de São Paulo a ideia de uma "história regional" não é uma questão urgente e cotidiana, ao contrário do que ocorre com esses mesmos personagens no Rio Grande do Sul, no Paraná ou no Pará. Ao pensar na independência, por exemplo, além de todas as questões mais estruturais, os alunos de São Paulo frequentemente lembrarão do Ipiranga, do grito de D. Pedro e, se necessário, verão a província como partícipe dessa história na figura de José Bonifácio. Ao contrário disso, alunos do Pará não terão sua realidade contemplada por essa narrativa que se apresenta como nacional. ${ }^{17}$ No entanto, não são justamente episódios como os ocorridos no Pará, marcados por um conflito armado duro e longo, que põe em xeque a ideia de uma independência pacífica no Brasil? Isso é o específico, o detalhe, ou algo a ser debatido em todos os níveis da formação em História? E o medo das elites baianas durante o processo da independência com o possível levante de um "partido negro", evento celebrizado por João José Reis, não deveria ser uma imagem tão popular quanto o "grito do Ipiranga"? Esses episódios não fazem parte de uma história nacional complexa?

Este artigo busca fazer alguns apontamentos sobre o enorme potencial de um olhar mais atento para as províncias sobre os grandes modelos historiográficos do Brasil do século XIX. Para tanto, as escolhas do recorte espacial não devem se prender aos 
territórios das antigas províncias, mas mover-se para dentro e para fora dessas fronteiras, de acordo com a lógica dos problemas a serem analisados. Nessa direção, busca-se demonstrar, na primeira parte do artigo, que nada mais está se propondo do que o exercício a que já foram submetidos historiadores preocupados com recortes espaciais maiores, já cientes da impossibilidade de restringir seus recortes às atuais fronteiras do Brasil, especialmente durante o período colonial. Na segunda parte do artigo, buscam-se alguns exemplos desses impasses e possibilidades a partir de pesquisas sobre a história do Grão-Pará no XIX.

\section{O recorte espacial e a visão de mundo do historiador}

Como dito anteriormente, ao propor a discussão de qualquer problema, seja ao ensinar ou pesquisar, o historiador sempre faz os recortes que julga serem os mais adequados para compreender o objeto em estudo. Esses recortes nunca são neutros. A escolha de uma cronologia, por exemplo, expressa uma determinada compreensão que temos do passado. Ainda se fixando no problema da formação do Brasil como um país independente, podemos explicar ou pesquisar esses episódios com diferentes recortes cronológicos. Por exemplo, pode-se fixar o estudo ou a aula apenas nos episódios de 1822, atribuindo-se a ruptura política à suposta e hoje questionada tentativa de "recolonização" do Reino do Brasil pelas Cortes de Lisboa. Esquece-se, assim, que muito tempo depois ainda existiam províncias americanas ligadas a Portugal, como o Pará e o Maranhão. ${ }^{18}$ Essa é uma abordagem que reduz o processo a uma trama palaciana.

Por outro lado, aqueles que enxergam o surgimento de países independentes na América como um desdobramento da crise do Antigo Regime, e no seu interior da derrocada do Antigo Sistema Colonial e do surgimento da moderna ideia de nação, com frequência retrocedem sua análise em muitos anos e décadas antes de 1822, não raras vezes tendo seu ponto de partida na segunda metade do XVIII. ${ }^{19}$ Há ainda aqueles que estendem a análise para anos depois de 1822, seja mostrando como foi errático o processo de construção 
Entre o nacional e o regional: uma reflexão sobre a importância...

do Brasil como país independente, seja enfatizando que havia outras coisas em disputa para além da ruptura ou não com Lisboa. ${ }^{20} \mathrm{Em}$ todos esses casos é uma determinada visão do mundo, necessariamente ancorada também nos resultados de pesquisa, leitura e reflexão, que sustentam essa opção do historiador.

Da mesma forma, o recorte espacial diz muito sobre a nossa compreensão do passado. Nesse sentido, tanto no ensino como na pesquisa em História é muito comum nos reportarmos à ideia de "Brasil Colônia" para definir territorialmente um objeto de estudo, como se ela representasse uma unidade dada pela natureza, com características desde sempre singulares. No entanto, essa ideia faz sentido? Apesar de ser ainda muito utilizado - inclusive como nome de disciplina em graduações em História - a ideia de "Brasil Colônia" hoje enfrenta uma severa oposição. Símbolo famoso desse questionamento foi a escolha do subtítulo "Cotidiano e vida privada na América portuguesa" para o primeiro volume da coleção "História da Vida Privada no Brasil". Fernando Novais, diretor da coleção, explicou de forma muito didática a razão dessa opção: pretendia-se, assim, evitar o anacronismo, pois os homens que viveram na colônia portuguesa na América não podiam prever o Estado independente que se formaria no século XIX (NOVAIS, 1997, p. 17). Apesar do termo Brasil ser muito utilizado mesmo antes do XIX, como lembrou um deputado na constituinte de 1823, este era um vocábulo que reportava a uma ideia geográfica e não a uma unidade política, pois os habitantes da colônia se identificavam como portugueses até a ruptura com Lisboa e a formação de um novo pacto (RODRIGUES, 1974 , p. 57-58). ${ }^{21}$ Os ingleses, por exemplo, utilizavam o termo Brasil no plural (Brazils), pois não identificavam a colônia como uma unidade (MELLO, 2004, p. 18; DONGHI, 1985, p. 22-36). Se não bastasse tudo o que foi dito acima, nunca é demais lembrar que a colônia portuguesa na América foi durante a maior parte do tempo dividida em dois Estados, um ao norte e outro ao sul.

Apesar da inexistência do Brasil como uma unidade até o XIX parecer uma obviedade, a força dessa ideia, ainda muito vulgarizada, nutre-se da frequente utilização dos territórios coloniais como "mito de origem" das historiografias que embasaram não só nacionalismos, mas também outras formas de identidades, como 
a regional (PIMENTA, 2002; CHIARAMONTE, 1989). Assim, se o termo "Brasil colônia" não faz sentido, o que dizer de ideias como o "Amapá no século XV" ou "a independência no Paraná”?

Não se trata de um preciosismo, ou uma reflexão que só interessa a um pesquisador especializado no período. Ao invés disso, pensar nessas questões é algo fundamental para a nossa prática como historiador no ensino e na pesquisa. Na sala de aula, por exemplo, este cuidado é fundamental para que o aluno perceba que os homens do passado se guiavam por uma lógica diferente daquela que hoje ele compartilha. Da mesma forma, só assim poderá entender que o Brasil ou o Pará são construções históricas e não elementos da natureza. Para que isso seja possível, no entanto, é fundamental que o profissional em História tenha noção de como é difícil estabelecer o nosso recorte espacial, de forma que ele faça sentido. Ao mesmo tempo, esse cuidado é necessário para fugirmos do anacronismo que recorrentemente cometemos ao estabelecermos esses recortes em função de identidades que apenas hoje fazem sentido.

É preciso ter percepção do que é a parte e o que é o todo. E, ainda mais do que isso, é preciso saber que essa resposta irá variar dependendo da pergunta que estamos fazendo. Por exemplo, se estamos querendo entender a colonização, é necessário perceber que a atuação portuguesa na América é apenas um desdobramento de uma série de transformações que acontecem nesse período na Europa (NOVAIS, 1985). Da mesma forma, a compreensão da atuação portuguesa na América perde muito quando pensamos que o todo é o chamado "Brasil Colônia" e não percebemos que as ações metropolitanas se guiavam pelas preocupações de um Império espalhado por vários continentes.

Apesar disso, é inegável que a nossa formação historiográfica para pensar a colonização portuguesa e, consequentemente, quase a totalidade do material didático disponível, tem seu foco no dito "Brasil Colônia". Foram raros os autores como Charles Boxer que buscaram entender a colonização portuguesa como um sistema em que os seus administradores tomavam decisões pensando não apenas em uma localidade, mas tendo em mente o jogo de xadrez da política internacional que não podia ser ignorado por um Império com domínios em vários continentes (BOXER, 1973). Mais recentemente, 
Entre o nacional e o regional: uma reflexão sobre a importância...

alguns historiadores e grupos de pesquisa têm buscado reverter essa tendência com estudos que buscam perceber a sincronia das ações portuguesas em suas diversas colônias (FRAGOSO; BICALHO; GOUVEIA, 2001). Outros estudos de grande mérito nessa direção são aqueles que evidenciam as trajetórias da alta nobreza portuguesa recrutada para a administração das colônias, pois deixam evidente que os mesmos homens que em determinado momento estavam governando na África, poucos anos depois estavam na América, na Ásia, ou mesmo em algum cargo de prestígio em Lisboa (SOUZA, 2006; MONTEIRO, 2001).

Luiz Felipe de Alencastro exemplifica muito bem como, dependendo da nossa pergunta, esse recorte no "Brasil Colônia" pode limitar a nossa compreensão do passado: ao falar da ocupação holandesa no nordeste do XVII, Alencastro lembra que pouquíssimos historiadores perceberam como a África teve um papel crucial nesse confronto. Ao contrário disso, os holandeses logo se deram conta que para dominar Pernambuco era crucial conquistar Angola, já que essa outra colônia portuguesa se convertera no polo exportador de mão-de-obra escrava para o nordeste. Da mesma forma, na luta pela reconquista dessa parte da América pelos lusos, teve papel decisivo a bem-sucedida retomada de Angola que, por sua vez, se converteu em moeda de troca para premiar todos que tinham se empenhado na guerra da Restauração Pernambucana (ALENCASTRO, 2008; ALENCASTRO, 2000). Nesse sentido, as observações de Alencastro são importantes não só por demonstrar que episódios frequentemente pensados como restritos ao "Brasil Colônia" tinham uma lógica intercontinental para os homens do período. Mais do que isso, a descrição dessas conexões na guerra da Restauração Pernambucana exemplifica a ideia de Alencastro de que para a compreensão da formação do Brasil é necessário atentar para o Atlântico Sul. Ou seja, para ele os historiadores, quando superam os limites do "Brasil Colônia", só dão importância às relações entre a América e a Europa. No caso da ocupação holandesa no nordeste, por exemplo, no contexto internacional costuma-se lembrar dos conflitos entre a Espanha e a Holanda e se esquece que os destinos da colônia portuguesa no Novo Mundo estavam diretamente ligados às possessões lusas na África. Esse vício do nosso olhar sobre o 
passado, altamente eurocêntrico, tem sido lentamente modificado pela inclusão de disciplinas de História da África nas universidades e pela obrigatoriedade da história e da cultura afro-brasileira no ensino básico. ${ }^{22}$

Outro exemplo pode ser dado a partir de um tema caro aos paraenses: o Diretório Pombalino. Muitos são os debates sobre as modificações implantadas por Pombal no trato com os índios, primeiramente na Amazônia e depois no restante da América. Há autores, inclusive, que insistem que a particularidade amazônica foi o que moldou a política do Diretório (COELHO, 2005). Apesar disso ser verdade em grande medida, as reformas empreendidas no Estado do Grão-Pará e Maranhão estavam em estreita consonância com os ajustes empreendidos por Portugal no tocante à mão-de-obra em seus domínios espalhados por vários continentes. No mesmo período, proibia-se igualmente a escravização dos chineses em territórios lusos, assim como o trabalho cativo africano era igualmente vetado na sede do Império Português (DOMINGUES, 2000, p. 37-41 e 67-76; NOVAIS; FALCON, 2005). O outro lado dessa política, muitas vezes não percebida, era que ao mesmo tempo em que eram proibidos o trabalho escravo de índios na América, de chineses na Ásia e de africanos na Europa, o tráfico de cativos vindos das colônias portuguesas na África era fortemente incrementado através das companhias monopolistas. Olhando-se isoladamente cada região não se percebe que essa era uma política geral visando regular os fluxos de mão-de-obra em todo o Império de forma a potencializar os lucros do tráfico de braços (NOVAIS; FALCON, 2005).

Com tudo isso não se quer advogar aqui que qualquer pesquisa em História deve pensar em uma escala planetária. Ao contrário disso, o que se quer apontar é que o nosso recorte espacial é sempre dado pelas perguntas às quais se quer responder, seja em sala de aula ou na pesquisa. Mais do que isso, as ponderações aqui expressas visam atacar um preconceito corrente na historiografia: a ideia de que estudos com foco "nacional" - mesmo que isso seja ancorado no questionável "Brasil Colônia" ou em pesquisas restritas a São Paulo, Rio de Janeiro ou Minas Gerais - são obras de grande fôlego por terem uma visão do todo, ao contrário de trabalhos dedicados ao estudo de uma região que seriam sempre parciais e, portanto, 
Entre o nacional e o regional: uma reflexão sobre a importância...

uma história menor. Estudar o "Brasil", o "Império Português" ou o "Pará" não são, por princípio, escolhas certas ou erradas.

\section{Potencialidades e riscos de histórias focadas em regiões}

Como dito acima, nenhum evento nasce como história regional ou local. É a nossa visão de mundo que seleciona e hierarquiza os episódios, definindo o lugar que eles terão na nossa compreensão do passado. Nesse sentido, aqueles acontecimentos tidos como história regional recebem, geralmente, dois tratamentos.

No primeiro caso, nos livros com a pretensão de contar uma história nacional, esses eventos são ignorados - a não ser quando são içados à categoria "superior", como a Confederação do Equador - ou tratados como uma complementação ao que seria a narrativa principal. Exemplar dessa última postura é o livro de Francisco Adolfo de Varnhagen - História da Independência do Brasil - em que toda a primeira parte do volume é composta por uma sequência principal de fatos - tidos como nacionais - acrescido por uma espécie de anexo no qual são descritos os acontecimentos particulares de algumas províncias no período de ruptura com Lisboa (VARNHAGEN, 1957).

Por outro lado, costumeiramente, o tratamento dispensado pela literatura que se assumiu como história regional foi o de isolar os eventos estudados, como se eles tivessem uma lógica autônoma. Ainda que não seja o melhor exemplo, em grande medida pode-se identificar esse comportamento na maior obra amazônica do gênero no século XIX - o Motins Políticos de Domingos Antonio Raiol (RAIOL, 1970). Na obra de Raiol poucas são as conexões entre os eventos ocorridos em território paraense e outros centros de poder. Nesse sentido, em Motins Políticos opera-se justamente o inverso da lógica que guiou o livro de Varnhagen: os acontecimentos no Rio, em Lisboa ou em outras regiões aparecem como um apêndice que serve, quando muito, para situar o contexto em que ocorreram as ações principais narradas no livro.

Nos dois tratamentos o problema é que a seleção dos eventos a serem pesquisados ou ensinados se dá em função de uma 
lógica geográfica que muitas vezes apenas hoje faz sentido e não em torno de um problema a ser respondido ou refletido. Voltando ao problema da independência, é muito salutar perceber que o livro Motins Políticos descreve esses acontecimentos no Pará como se toda a lógica e articulação política dos protagonistas acompanhados por ele estivessem restritas às fronteiras do Pará. Ao contrário disso, novos estudos demonstram como a articulação de grupos em várias províncias foi determinante para as tomadas de decisão na província (MACHADO, 2005).

Desse modo, a questão fundamental é: por que razões um historiador focaria sua pesquisa em uma região ou se prestaria a dar aulas nesse formato? Por que seguir este caminho e não os temas historiográficos que têm maior prestígio social? Essa é uma pergunta obrigatória e que não tem uma resposta óbvia. Estudar ou ensinar sobre os acontecimentos no Pará ou em Bragança não são coisas necessariamente boas ou ruins em si mesmas.

Feitas essas considerações, também se deve levar em conta o grande potencial a ser trabalhado pelo historiador que resolve observar os eventos "locais" e "regionais" para responder suas questões no ensino e na pesquisa. Por exemplo, muito dos que defendem a dita história local advogam que ela pode dar destaque à trajetória dos homens que em seu tempo não pertenciam aos estratos dominantes e daria relevância a cenários conhecidos pelos alunos e pelos leitores. Ou seja, isso reforçaria a ideia de que a história não só pertence como é modificada pela luta e pelas ações de todos os homens. Esse pode ser, de fato, um caminho frutífero. No entanto, ao reconstruir as trajetórias particulares ou da região é sempre necessário que também se integre isso a contextos mais amplos. Por exemplo, ao reinterpretar como viviam os escravos em uma fazenda da localidade, se na sala de aula ou em um texto não articularmos esse debate à questão mais geral da mão de obra - o tráfico internacional, as outras formas de trabalho compulsório, o papel dos homens livres pobres etc - corremos o risco de oferecer apenas o exótico.

Em síntese, recomenda-se que os eventos ocorridos na localidade e na região não sejam vistos sob a ótica da particularidade ou do fragmento. Ao invés disso, defende-se aqui que o real papel desses 
Entre o nacional e o regional: uma reflexão sobre a importância...

estudos é iluminar os contextos mais amplos dos quais foram parte, já que a nossa historiografia consagrou grandes modelos explicativos que, em geral, não encontram respaldo no passado das zonas periféricas. Ou seja, o desafio é desfazer a seleção e hierarquização dos eventos já consagrada em nossas "obras gerais" e, mesmo, na chamada "historiografia regionalista".

Tomem-se dois exemplos: o primeiro deles, voltando ao processo de independência do Brasil. ${ }^{23}$ Como já dito, ainda prevalece, tanto no senso comum como em nossa historiografia, a ideia de que o Brasil se tornou um país independente de forma pacífica, com pequeno ou quase nulo envolvimento da população no processo. Essa tese foi construída a partir de diferentes olhares. Varnhagen, por exemplo, esmerou-se por tornar natural a passagem da colônia para o país independente, como se a primeira, inclusive seu território e povo, fosse uma herança do segundo (PIMENTA, 2002, p. 38-42). Por sua vez, autores como Caio Prado Jr., Florestan Fernandes e Luiz Felipe de Alencastro, entre muitos outros, defenderam a ideia de que a ruptura com Lisboa e a manutenção do território do Império do Brasil decidiu-se "por cima", já que teria sido habilmente construída por um acordo entre as elites da antiga América Portuguesa (ALENCASTRO, 1985; PRADO JR., 1975). No entanto, ao analisarmos esse processo tendo especial atenção aos acontecimentos no Pará esse modelo não encontra respaldo. Chama a atenção não só as incertezas quanto à integração da província à órbita do Rio de Janeiro, mas também a persistência de grandes conflitos até 1825, com grande envolvimento de indígenas ${ }^{24}$, escravos e desertores (COELHO, 1978; MACHADO, 2010; SOARES, 2010). Tudo isso deixa patente que estava em jogo mais do que a decisão se os homens do Pará seriam portugueses ou brasileiros: o que estava em disputa era o modelo de Estado a ser implantado, pois enquanto alguns grupos desejavam barrar ao máximo as mudanças sociais, outros enxergavam a oportunidade para uma revolução. Não é por acaso que, ainda em 1824, grupos de indígenas lutavam contra a exploração compulsória da sua mão-de-obra sob o argumento de que estavam em guerra para fazer vencer a "verdadeira causa da independência” (MACHADO, 2007).

Anos 90, Porto Alegre, v. 24, n. 45, p. 293-319, jul. 2017 
Desde Raiol, os conflitos ocorridos no Pará nesse período foram quase sempre entendidos como uma particularidade. Ao invés disso, acredita-se que esses confrontos abrem uma nova perspectiva para pensar a formação do Império do Brasil como um todo. Novos estudos têm revelado como questões sociais e o próprio modelo do Estado não foram alvos de disputas apenas no Pará, mas também na Bahia, Pernambuco, Maranhão, entre outros (BERNARDES, 2003; KRAAY, 2002; ASSUNÇÃO, 2005). Os avanços dessas pesquisas vão tornando cada vez mais insustentáveis os grandes modelos explicativos da independência do Brasil.

Outro exemplo que pode ser dado diz respeito ao parlamento no Império do Brasil. Ainda são tímidos os estudos sobre essa instituição, sendo ainda pior o seu tratamento nos materiais didáticos para o ensino básico. Nesses últimos textos, em geral, o parlamento só aparece para lembrar a dissolução da constituinte de 1823, as fraudes nas eleições e para ressaltar a versão de que o Imperador criava e dissolvia ministérios ao seu bel-prazer. Em resumo, prevalece nos textos de divulgação a visão historiográfica construída pelos próprios agentes políticos no século XIX e sintetizada por Sérgio Buarque de Holanda: para essa corrente, todo o sistema representativo no Império do Brasil era uma farsa, pois o Imperador tinha todo o controle através do poder moderador (HOLANDA, 1997). Por extensão, não haveria nenhuma conexão entre legislativo e a realidade nas províncias.

Contudo, novos estudos sobre o parlamento e o sistema representativo no Império do Brasil têm demonstrado que senadores e deputados eram uma peça importante do jogo político e não um mero objeto decorativo (GREGÓRIO, 2012; DOLHNIKOFF, 2009; DOLHNIKOFF, 2007). Por sua vez, chamam a atenção trabalhos como a tese de Vantuil Pereira, que analisam o parlamento para além do que acontecia em plenário, sublinhando as relações entre essa instituição e o conjunto da população. Nessa obra, Pereira examinou petições, requerimentos e representações enviadas por particulares de todas as partes do país, inclusive do Pará, em que se recorria aos parlamentares para fazer reivindicar direitos e o cumprimento das leis (VANTUIL, 2010). 
Entre o nacional e o regional: uma reflexão sobre a importância...

Nesse sentido, a análise de eventos locais e regionais é fértil terreno para repensar o papel do legislativo na política das províncias, tradicionalmente concebidas como sensíveis apenas às intervenções dos ministérios. Ao contrário disso, por exemplo, hoje sabemos que jornais paraenses acompanhavam com atenção as votações no Rio de Janeiro, faziam campanha a favor e contra candidatos (MACHADO, 2009a; MACHADO, 2009b; MACHADO, 2011). ${ }^{25}$ Da mesma forma, há um grande volume de representações enviadas de vilas paraenses para a Câmara e o Senado reclamando do golpe de 1831 que depôs o Visconde de Goiana da Presidência da província (MACHADO, 2011). Essas representações, assim como os embates no Conselho Geral de Província, são demonstrações da importância dada pelos paraenses ao Parlamento, então visto como uma instituição que garantiria a liberdade e o direito.

Dessa forma, por exemplo, pode-se investigar o Parlamento no Império do Brasil num sentido inverso do costumeiro. Afinal, qual era a conexão entre a política nas províncias e o jogo de forças no parlamento? Voltando ao exemplo do golpe de 1831, não é possível compreender os desdobramentos desse acontecimento na província sem atentar para os compromissos e os juízos do Parlamento (MACHADO, 2011). Dessa forma, não havia isolamento político mesmo em uma província afastada como o Pará. Igualmente, não é possível compreender a atuação de deputados e senadores do Pará sem considerar suas ligações com a província, a não ser que se queira insistir em uma desconexão dos parlamentares com o restante da sociedade, como de certa forma preconizou José Murilo de Carvalho (CARVALHO, 2011).

Em nossas salas de aula ou em nossas pesquisas não valerá mais a pena trilhar esse novo caminho do que repetir os velhos modelos pensados a partir do Rio de Janeiro? 


\section{BETWEEN THE NATIONAL AND THE REGIONAL : A REFLECTION ON THE IMPORTANCE OF THE SPATIAL CUTTINGS IN THE RESEARCH AND IN THE HISTORY TEACHING}

Abstract: When proposing the discussion of any problem, teaching or researching, the historian always makes a spatial cutting which judges to be the most appropriate to understand the object in study. That is a crucial problem for any historian, but still more evident for those who study or live in areas considered as peripheral, like Pará, since the History taken as "national" frequently ignores or relegates to the second plan the events happened at those places. Starting from research examples about the history of Grão-Pará during the independence and the Empire of Brazil, this article intends to contemplate about four main points: 1) the spatial cutting is a methodological subject and, as such, it reflects the vision of the historian professor/researcher; 2) the potential of the study and teaching on peripheral areas to problematize the main national issues; 3 ) the need to problematize the local events in wider contexts; 4) the different senses of the "regional History" in São Paulo and in Pará.

Keywords: Methodology. Spatial cuttings. Grão-Pará.

\section{Notas}

${ }^{1}$ Em um pequeno volume organizado pelo próprio Museu Paulista, Ulpiano Meneses - que foi seu diretor - publicou uma série de pequenos textos em que abordava a necessidade de abordar criticamente os museus históricos, ao mesmo tempo em que situava a singularidade do Museu Paulista (MENESES, 1992). Sob um outro enfoque, para uma análise crítica de um discurso expositivo, veja (PAIVA, 2015).

${ }^{2}$ Entre outras colaborações, John Monteiro demonstrou que os bandeirantes não fixaram novas fronteiras porque não se fixavam nos terrenos alcançados, assim como estavam longe de serem povoadores de novas terras: ao contrário, Monteiro afirma que os bandeirantes eram despovoadores, uma vez que eliminavam a população indígena das áreas que alcançavam (MONTEIRO, 1994).

${ }^{3}$ Sobre a decoração do interior do Museu Paulista e o quadro de Pedro Américo, veja MAT'TOS, 2003; OLIVEIRA; MAT'TOS, 1999. É preciso lembra que o quadro de Pedro Américo estava no monumento à independência muito antes das reformas dirigidas por Taunay. Aliás, um dos objetivos da construção do monumento era abrigar o quadro. Antes da recente reforma, o próprio Museu Paulista expunha textos ao visitante em que fazia uma leitura crítica da proposta expositiva organizada por Taunay.

Anos 90, Porto Alegre, v. 24, n. 45, p. 293-319, jul. 2017 
${ }^{4}$ Para a grade curricular da UFPR, veja $<$ http://www.humanas.ufpr.br/portal/ historia/graduacao/disciplinas/>. Para grade curricular da UFRGS, veja $<$ http:// www.ufrgs.br/ufrgs/ensino/graduacao/cursos/exibeCurso?cod_curso=333>. Para a grade curricular da UFPE, veja <https://www.ufpe.br/proacad/images/ cursos_ufpe/historia_bac_perfil_0200.pdf>. Acesso em: 08 nov. 2015.

${ }^{5}$ Para a grade curricular da UFMA, veja $<$ https://sigaa.ufma.br/sigaa/link/public/ curso/curriculo/14471851>. Para a grade curricular da UFC, veja $<$ https://si3. ufc.br/sigaa/public/curso/curriculo.jsf;jsessionid=E91F1CA2A9078ABF1295CC03D5DE2D27.node142>. Acesso em: 08 nov. 2015.

${ }^{6}$ Para a grade curricular da UFPA, veja < http://www.ufpa.br/historia/projeto $\% 20$ pedag\%C3\%B3gico.PDF>. Acesso em: 08 nov. 2015.

${ }^{7}$ Partindo de uma análise marxista, Sandra Jatahy Pesavento arrisca uma explicação para o fato da história de São Paulo e Rio de Janeiro se confundirem com a história nacional: para ela, isso se daria porque nestas regiões repousaria o centro do capitalismo no Brasil. Como contraponto, diz que o Rio Grande do Sul nunca alçou esta condição, mesmo durante o governo de Getúlio Vargas, o que teria reforçado a concepção da história gaúcha como uma singularidade (PESAVENTO, 1990).

${ }^{8}$ Parâmetros para a Educação Básica do Estado de Pernambuco - Parâmetros Curriculares de História - Ensino Fundamental e Médio. Udime, 2013. Disponível em: <http://www.educacao.pe.gov.br/portal/upload/galeria/4171/historia_parametros_efm2013.pdf>. Acesso em: 17 nov. 2015. Os parâmetros curriculares aqui citados foram disponibilizados por Antonio Simplício de Almeida Neto durante uma disciplina que ministramos em conjunto.

${ }^{9}$ Currículo Referência da Rede Estadual de Educação de Goiás (2012). Disponível em: <http://www.seduc.go.gov.br/imprensa/documentos/arquivos/Curr\%C3\%ADculo\%20Refer\%C3\%AAncia/Curr\%C3\%ADculo\%20Refer\%C3\%AAncia $\% 20$ da $\% 20$ Rede $\% 20$ Estadual $\% 20$ de $\% 20$ Educa $\%$ C3 $\%$ A7\%C3\%A3o $\% 20$ de\%20Goi\%C3\%A1s!.pdf>. Acesso em: 17 nov. 2015.

${ }^{10}$ Referencial Curricular - Lições do Rio Grande - Ciências Humanas e suas tecnologias (2009). Disponível em: <http://www.gipeonline.com.br/pdf/Curriculares/volume_5.pdf $>$. Acesso em: 17 nov. 2015.

${ }^{11}$ Disponível em: <http://www.fnde.gov.br/pnld-2016/>. Acesso em: 17 nov. 2015. Deve registrar que, numa direção contrária a de outras constatações desse artigo, no PNLD há vários livros de história e geografia focados em São Paulo. ${ }^{12}$ Discurso do ministro Renato Janine Ribeiro, em 16 de setembro de 2015. Transcrito no site G1: <http://g1.globo.com/educacao/noticia/2015/09/escolas-devem-ter60-do-conteudo-curricular-padronizado-diz-mec.html>. Acesso em: 16 dez. 2015. ${ }^{13}$ Obviamente, há diversas manifestações contrárias a essa decisão do governo paulista, sobretudo por torna o professor um mero cumpridor de tarefas. Veja CIAMPI et al., 2009, p. 361-382; BITTENCOURT, [s.d.]. 
${ }^{14}$ Proposta curricular do Estado de São Paulo: História. Disponível em: <http:// www.rededosaber.sp.gov.br/portais/Portals/18/arquivos/Prop_HIST_COMP_ red_md_20_03.pdf $>$. Acesso em: 10 nov. 2010. Veja também de CIAMPI et al, 2009, p. 375-382 e BITTENCOURT, 2009, p. 159-160.

${ }^{15}$ Para a ANPUH 2015, veja <http://www.snh2015.anpuh.org/simposio/public>; Para a ANPUH 2013, veja <http://www.snh2013.anpuh.org/simposio/public>. O simpósio citado acima é o de número 43.

${ }^{16}$ Pesavento faz duras críticas à forma como como o ensino de História para a educação básica no Rio Grande do Sul tem se prestado a perpetuar a memória dos chamados "grandes homens", assim como solidificar o mito da especificidade gaúcha (PESAVENTO, 1990). Veja também BITTENCOURT, 2009.

${ }^{17}$ Para um resumo do debate historiográfico sobre o processo de independência no Pará, entre outros, veja MACHADO, 2010; COELHO, 1993; SOUZA JR., 1997. ${ }^{18}$ Em um texto bastante contundente, Márcia Berbel demonstra que não havia fundamentos reais para uma tentativa de recolonização das Cortes, atribuindo ao jogo político a consagração dessa idéia (BERBEL, 2005). Por outro lado, a experiência constitucional portuguesa permitiu uma liberdade política até então jamais experimentada na América (BERNARDES, 2006). Mesmo durante a constituinte de 1823 havia dúvidas sobre a integração ou não de províncias como Maranhão e Pará ao Império do Brasil, como atesta, entre outras coisa, a manifestação do deputado José de Alencar. Sobre essa fala de Alencar, veja de RODRIGUES, 1974, p. 113-117.

${ }^{19}$ Veja, entre outros, NOVAIS, 1995; DONGHI, 1985; JANCSÓ; PIMENTA, 2000; JANCSÓ, 2003.

${ }^{20}$ Nesse sentido, alguns autores mostram que havia diferentes entendimentos do significado da independência. Em algumas províncias, camadas desprestigiadas da sociedade, como negros e índios, entendiam a independência como uma revolução (ASSUNÇÃO, 2005; MACHADO, 2010).

${ }^{21}$ A exemplo de vários outros historiadores, Laura de Mello e Souza afirma que foi no interior da alta burocracia portuguesa que o Brasil foi visto primeiramente como uma unidade, não sendo esta uma percepção compartilhada pela população local (SOUZA, 2006, p. 17).

${ }^{22}$ Ainda há pouco material disponível para o ensino básico. Veja de MATTOS, 2007.

${ }^{23}$ Para uma ampla revisão da historiografia sobre a independência do Brasil, veja COSTA, 2005.

${ }^{24}$ Trata-se de um tipo específico de indígena, os chamados "índios avilados", "índios cristãos" ou "tapuios" que viviam espalhados pelas vilas, povoados e pela cidade do Pará, sendo que estes homens constituíam ainda no começo do século XIX a maior parte da mão de obra da província. Sobre estes indivíduos pesava a legislação de 1798 que tornara estes indígenas livres de qualquer tutela, 
Entre o nacional e o regional: uma reflexão sobre a importância...

equiparando-os aos demais vassalos do monarca português, mas ao mesmo tempo criara normas que os obrigavam a trabalhar de maneira compulsória em obras públicas e privadas. Sobre os tapuios e a exploração compulsória de sua mão-de-obra, veja de CLEARY, 1988; MOREIRA NETO, 1988; FREIRE, 2004, cap. 4; PRADO JR, 1972, p. 98-99; SAMPAIO, 2012; HARRIS, 2010; SANTOS, 2014, MACHADO, 2010.

${ }^{25}$ Sobre os jornais paraenses, veja também de SALLES, 1992; BARATA, 1973.

\section{Referências}

ALENCASTRO, Luiz Felipe de. Desagravo de Pernambuco e glória do Brasil. A obra de Evaldo Cabral de Mello. In: SCHWARCZ, Lilia Moritz (Org.). Leituras críticas sobre Evaldo Cabral de Mello. Belo Horizonte; São Paulo: UFMG; Perseu Abramo, 2008.

. Le commerce des vivants: traite d'esclaves et "Pax Lusitana" dans l'Atlantique Sud. Doutorado, Paris: Université de Paris X, 1985-1986.

. O Trato dos Viventes: formação do Brasil no Atlântico Sul. São Paulo: Cia das Letras, 2000.

ASSUNÇÃO, Mattias Röhrig. Miguel Bruce e os "horrores da anarquia no Maranhão, 1822-27. In: JANCSE, István (Org.). Independência: história e historiografia. São Paulo: Hucitec; Fapesp, 2005.

BARATA, Manuel. Formaşão bistórica do Pará. Belém: UFPA, 1973.

BERBEL, Márcia Regina. A retórica da colonização. In: JANCSŁ, István (Org.). Independência: história e historiografia. São Paulo: Hucitec/Fapesp, 2005.

BERNARDES, Dênis Antonio de Mendonça. O Patriotismo Constitucional: Pernambuco, 1820-22. São Paulo: Hucitec/Fapesp; UFPE, 2006.

. Pernambuco e o Império (1822-24): sem constituição soberana não há união. In: JANCSÓ, István (Org.). Brasil: formação do Estado e da Nação. São Paulo; Ijuí: Hucitec/Fapesp; Unijuí, 2003.

BITTENCOURT, Circe Fernandes. Ensino de História: fundamentos e métodos. 3. ed., São Paulo: Cortez, 2009.

. Livros didáticos de história: práticas e formação docente. In: ENDIPE, 15., Belo Horizonte. Convergências e tensões no campo da formação e do trabalho docente: currículo, ensino de educação física, ensino de geografia, ensino de história, escola, família e comunidade. Belo Horizonte: Autêntica, 2010. 
. Propostas curriculares de História: continuidades e transformações. In: BARRETO, Elba Siqueira de Sá (Org.). Os currículos do Ensino Fundamental para as escolas brasileiras. São Paulo: Fundação Carlos Chagas e Campinas: Autores Associados, 1998.

BOXER, Charles R. Salvador de Sá e a luta pelo Brasil e Angola: 1602-1686. São Paulo: Editora Nacional; Edusp, 1973.

CARVALHO, José Murilo de. A Construção da Ordem / Teatro das Sombras. Rio de Janeiro: Civilização Brasileira, 2011.

CHIARAMONTE, José Carlos. Formas de identidad en el Rio de la Plata luego de 1810. Boletin del Instituto de Historia Argentina y Americana Dr. E. Ravignani. Terceira série, n. 1, 1. sem. de 1989.

CIAMPI, Helenice et al. O Currículo Bandeirante: a proposta curricular de história no estado de São Paulo, 2008. Revista Brasileira de História, São Paulo, v. 29, n. 58, p. 361-382, 2009.

CLEARY, David. Lost Altogether to the Civilised World: Race and Cabanagem in Northern Brazil, 1750 to 1850. Comparative Studies in Society and History, v. 40, n. 1, 1988 .

COELHO, Geraldo Mártires. Ação e reação na província do Pará: o conflito políticosocial de 1823. Niterói: UFF, 1978. Dissertação de mestrado.

- Anarquistas, Demagogos e Dissidentes: a imprensa liberal no Pará de 1822. Belém: CEJUP, 1993.

COELHO, Mauro Cezar. Do sertão para o mar: um estudo sobre a experiência portuguesa na América a partir da Colônia. O caso do Diretório dos Índios (1751-98). São Paulo: USP, 2005. Tese de doutoramento.

COSTA, Wilma Peres. A independência na historiografia brasileira. In: JANCSÓ, István. Independência: história e historiografia. São Paulo: Hucitec/Fapesp, 2005.

Dolhnikoff, Miriam. O pacto imperial: origens do federalismo no Brasil. São Paulo: Globo, 2007.

. Representação na monarquia brasileira. Almanack Braziliense, São Paulo, n. 9, maio 2009. Disponível em: <www.almanack.usp.br>.

DOMINGUES, Ângela. Quando os indios eram vassalos: colonização e relações de poder no norte do Brasil na segunda metade do XVIII. Lisboa: Comissão Nacional para a comemoração dos descobrimentos Portugueses, 2000.

DONGHI, Tulio Halperín. História de América Latina. Reforma y Disolución de Los Impérios Ibéricos (1750-1850). v. 3. Madri: Alianza Editorial, 1985. 
Entre o nacional e o regional: uma reflexão sobre a importância...

FRAGOSO, João; BICALHO, Maria Fernanda; GOUVEIA, Maria de Fátima (Org.). O Antigo Regime nos Trópicos: dinâmica imperial portuguesa (séculos XVI-XVIII). Rio de Janeiro: Civilização Brasileira, 2001.

FREIRE, Ribamar Bessa. Rio Babel: a história das línguas na Amazônia. Rio de Janeiro: Atlântica, 2004.

GREGÓRIO, Vitor Marcos. Uma face de Jano: a navegação do rio Amazonas e a formação do Estado brasileiro (1838-1867). São Paulo: Anablume, 2012.

HARRIS, Mark. Rebellion on the Amazon: the Cabanagem, Race, and popular culture in the North of Brazil, 1798-1840. New York: Cambridge University Press, 2010.

HOLANDA, Sérgio Buarque de. O Poder Pessoal. In: . (Dir.). História Geral da Civilização Brasileira. t. II: O Brasil Monárquico. v. 5: do Império à República. Rio de Janeiro: Bertrand Brasil, 1997.

JANCSÓ, István (Org.). Brasil: formação do Estado e da Nação. São Paulo: Fapesp/Hucitec; Unijuí, 2003.

. (Org.). Independência: história e historiografia. São Paulo: Hucitec/Fapesp, 2005.

JANCSÓ, István; PIMENTA, João Paulo G. Peças de um mosaico ou apontamentos para o estudo da emergência da identidade nacional brasileira. IN: MOTA, Carlos Guilherme (Org.). Viagem Incompleta: a experiência brasileira (1500-2000). Formação: Histórias. São Paulo: Editora Senac, 2000.

KRAAY, Hendrik. A Invenção do Sete de Setembro, 1822-1831. Almanack Braziliense, São Paulo, n. 11, p. 52-61, maio 2010. Disponível em: <www.almanack.usp.br>.

.Em outra cosia não falavam pardos, cabras e crioulos. O "recrutamento" de escravos na guerra de independência da Bahia (1822-23). Revista Brasileira de História, São Paulo, v. 22, n. 43, 2002.

MACHADO, André Roberto de A. A quebra da mola real das sociedades: a crise política do Antigo Regime Português na província do Grão-Pará (1821-25). São Paulo: Hucitec/Fapesp, 2010.

- Apontamentos para o estudo da reinvenção do Estado no Grão-Pará: 1823-25. In: COSTA, Wilma Peres; OLIVEIRA, Cecília Helena de Salles. De um império ao outro: formação do Brasil, séculos XVIII e XIX. São Paulo: Hucitec/ Fapesp, 2007.

. As esquadras imaginárias. No extremo-norte, episódios do longo processo de independência do Brasil. In: JANCSÓ, István (Org.). Independência: história e historiografia. São Paulo: Hucitec/Fapesp, 2005. 
. As "reformas em sentido federal". A atuação dos representantes do Grão-Pará no Parlamento e as expectativas na província em torno do Ato Adicional. Revista Estudos Amazônicos, v. 4, n. 1, 2009 (A).

. O Fiel da Balança: o papel do parlamento brasileiro nos desdobramentos do golpe de 1831 no Grão-Pará. Revista de História (USP), São Paulo, n. 164, 2011.

. Redesenhando Caminhos. O papel dos representantes do Grão-Pará na primeira legislatura do Império do Brasil (1826-1829). Almanack Braziliense, São Paulo, n. 10, nov. 2009. Disponível em: <www.almanack.usp.br> (B).

MATTOS, Claudia Valladão de. Da Palavra à Imagem: sobre o programa decorativo de Affonso Taunay para o Museu Paulista. Anais do Museu Paulista. São Paulo. v. 6/7, p. 123-145 (1998-1999). Editado em 2003.

MATTOS, Regiane Augusto de. História e cultura afro-brasileira. São Paulo: Contexto, 2007.

MELLO, Evaldo Cabral de. A outra independência: o federalismo pernambucano de 1817 a 1824. São Paulo: Editora 34, 2004.

MENESES, Ulpiano B. Museus Históricos: da celebração à consciência histórica. In: MUSEU PAULISTA (Org.). Como explorar um Museu Histórico. São Paulo: USP, 1992.

. Para que serve um museu histórico? In: MUSEU PAULISTA (Org.). Como explorar um Musen Histórico. São Paulo: USP, 1992.

. O Salão Nobre do Museu Paulista e o teatro da História. In: MUSEU PAULISTA (Org.). Como explorar um Museu Histórico. São Paulo: USP, 1992.

MONTEIRO, John Manuel. Os Negros da Terra: índios e bandeirantes nas origens de São Paulo. São Paulo: Cia das Letras, 1994.

MONTEIRO, Nuno Gonçalo F. Trajetos sociais e governo das conquistas: notas preliminares sobre os vice-reis e governadores-gerais do Brasil e da Índia nos séculos XVII e XVIII. In: FRAGOSO, João; BICALHO, Maria Fernanda; GOUVEIA, Maria de Fátima (Org.). O Antigo Regime nos Trópicos: dinâmica imperial portuguesa (séculos XVI-XVIII). Rio de Janeiro: Civilização Brasileira, 2001.

MOREIRA NETO, Carlos de Araújo. Índios da Amazônia, de maioria à minoria. 1750-1850. Petrópolis: Vozes, 1988.

NOVAIS, Fernando A. (Dir.). História da vida privada no Brasil. Cotidiano e vida privada na América portuguesa. v. 1. São Paulo: Cia das Letras, 1997.

. Portugal e Brasil na Crise do Antigo Sistema Colonial (1777-1808). 6. ed. São Paulo: Hucitec, 1995.

Anos 90, Porto Alegre, v. 24, n. 45, p. 293-319, jul. 2017 
Entre o nacional e o regional: uma reflexão sobre a importância...

NOVAIS, Fernando; FALCON, Francisco C. A extinção da escravatura africana em Portugal no quadro da política pombalina. In: NOVAIS, Fernando. Aproximações: estudos de história e historiografia. São Paulo: Cosac Naif, 2005.

OLIVEIRA, Cecília Helena de Salles. O Museu Paulista da USP e a memória da independência. Caderno CEDES, Campinas, v. 22, n. 58, p. 65-80, dez. 2002.

OLIVEIRA, Cecília Helena de Salles; MATTOS, Cláudia Valadão (Org.). O Brado do Ipiranga. São Paulo: Edusp/Museu Paulista/Imprensa Oficial, 1999.

PAIVA, Odair da Cruz. Migrar: experiências, memórias e identidades. Análise da exposição de longa duração do Museu da Imigração do Estado de São Paulo. In: SIMPÓSIO NACIONAL DE HISTÓRIA (ANPUH), 28., Florianópolis. Anais... Florianópolis: ANPUH, 2015. Disponível em: <http://www.snh2015. anpuh.org/site/anaiscomplementares>. Acesso em: 12 nov. 2015.

PEREIRA, Vantuil. Ao Soberano Congresso: os direitos do cidadão na formação do Estado Imperial Brasileiro (1822-31). São Paulo: Alameda, 2010.

PESAVENTO, Sandra Jatahy. História Regional e transformação social. In: SILVA, Marcos A. (Org.). República em migalhas: história regional e local. São Paulo: Marco Zero, 1990.

PIMENTA, João Paulo G. Estado e nação no fim dos impérios ibéricos no Prata (180828). São Paulo: Hucitec/Fapesp, 2002.

PRADO JR., Caio. Evolução política do Brasil e outros estudos. 9. ed. São Paulo: Brasiliense, 1975.

. Formação do Brasil Contemporâneo (Colônia). São Paulo: Brasiliense, 1972.

RAIOL, Domingos Antonio. Motins Políticos ou História dos Principais Acontecimentos Políticos da Província do Pará desde o ano de 1821 até 1835. Belém: UFPA, 1970. 3 v.

RODRIGUES, José Honório. A Assembleia Constituinte de 1823. Petrópolis: Vozes, 1974.

ROQUE, Carlos. História Geral de Belém e do Grão-Pará. Belém: Distribel, 2001.

SALLES, Vicente. Memorial da Cabanagem: esboço do pensamento político-revolucionário no Grão-Pará. Belém: CEJUP, 1992.

SAMPAIO, Patrícia Maria de Melo. Espelhos Partidos: etnia, legislação e desigualdade na colônia. Manaus: Editora da Universidade Federal do Amazonas, 2012.

SANTOS, Raquel Dani Sobral. A Construção do estatuto de cidadão para os índios do Grão-Pará (1808-1822). São Paulo: USP, 2014. Dissertação de Mestrado.

SILVA, Marcos A. (Org.). República em migalhas: história regional e local. São Paulo: Marco Zero, 1990. 
SILVA, Tomaz Tadeu da. Documentos de Identidade: uma introdução às teorias do currículo. Belo Horizonte: Autêntica, 1999.

SILVEIRA, Rosa Maria Godoy. Região e História: Questão de Método. In: SILVA, Marcos A. (Org.). República em migalhas: história regional e local. São Paulo: Marco Zero, 1990.

SOARES, Eliane Cristina Lopes. Roceiros e vaqueiros na Ilha Grande de Joanes no periodo colonial. Belém: NAEA/UFPA, 2002. Dissertação de mestrado.

SOUZA JR., José Alves de. Constituição ou revolução: os projetos políticos para a emancipação do Grão-Pará e a atuação política de Filipe Patroni (1820-23). Campinas: Unicamp, 1997. Dissertação de mestrado.

SOUZA, Laura de Mello. O Sol e a Sombra: política e administração na América Portuguesa do século XVIII. São Paulo: Cia das Letras, 2006.

VARNHAGEN, Francisco Adolfo de. História da Independência do Brasil até o reconbecimento pela Antiga metrópole, compreendendo, separadamente, a dos sucessos ocorridos em algumas provincias até essa data. 3. ed. São Paulo: Melhoramentos, 1957.

Recebido em: 04/05/2016 Aprovado em: 20/10/2016 
